\title{
Yeni Yazıtlar Işı̆̆ında Ata Yadigarı (Patroos) Tanrı Ksanthos Kültü
}

\section{The Cult of the Ancestral (Patroos) God Xanthos in Light of New Inscriptions}

\begin{abstract}
Nihal TÜNER ÖNEN*
Öz: İki başlık altında ele alınan buradaki makalede ilk olarak Lykialılar için antikçağ boyunca Letoon'la birlikte bölgenin idari ve kült merkezi olma özelliğini sürdürmüş olan Ksanthos antik kentinden ele geçen ve her biri farklı zamanlarda ata yadigarı tanrı Ksanthos'un rahipliğini yapmış kişilerin dikmiş oldukları heykellere ait olan dört yazıt tanıtılmıştır; ardından tanrı Ksanthos'un kimliğgine ilişkin var olan tartışmalar değerlendirilmiş ve yeni öneriler getirilmiştir. Bunu yaparken günümüze kadar, Homeros'un Ilias destanından itibaren adını bildiğimiz ve tanrıça Leto efsanelerine konu olmuş Ksanthos nehri ile özdeşleştirilen, fakat Lykia'da genellikle baş tanrı Apollon için kullanılan $\pi \alpha \tau \rho \tilde{\omega} o \varsigma$ epithetini alması dolayısıyla diğer nehir tanrılarından ayrılan ve kent üstü bir tanıma kavuşan söz konusu tanrının konumunun yazıtlar ve antik kaynaklar üzerinden gözden geçirilerek irdelenmesi gerekli görülmüştür. Tanrı Ksanthos kültünün kökenlerinin Hellenistik Dönem'e dayandığı düşünülse de burada ele alınan yazıtların tümü Roma İmparatorluk Dönemi'ne tarihlendirilmektedir. Yeni yayınlananlar dışında tanrı Ksanthos'a ilişkin kentten beş yazıt daha bilinmektedir. Bu durum söz konusu tanrıya ilişkin uzun süreli bu tapınımın önemini ortaya koymaktadır.
\end{abstract}

Anahtar sözcükler: Lykia, Ksanthos, Ata Yadigarı Tanrı Ksanthos, Patroos

Abstract: This article introduces four inscriptions carved on pedestals found in Xanthos which was the governmental and cult centre of Lycia together with Letoon during the antiquity. The statues were erected by different priests of Xanthos, the ancestral god in various times. The ancestral-god's controversialidentity is also considered, and new aspects are brought to this topic. It is also thought necessary to reconsider the god's place within the inscriptions and ancient sources. The ancestral god Xanthos was identified with the river Xanthos, which is known from the Iliad of Homeros, has a role in the myths of the goddess Leto. However, the ancestral god differs itself from the other river gods by having the epithet $\pi \alpha \theta \rho \tilde{\omega}$ o used generally for the chief god Apollo in Lycia. These inscriptions date from the Roman Period although it is thought that the cult of the ancestral god Xanthos had its origins in the Hellenistic period. In addition to these four inscriptions, five inscriptions mentioning the god Xanthos are known from the city. This situation reveals the significance of the longstanding worship to mentioned god.

Keywords: Lycia, Xanthos, The Ancestral God Xanthos, Patroos

Buradaki makalede Ksanthos antik kentinden ele geçen ve farklı zamanlarda ata yadigarı tanrı Ksanthos'un rahipliğini yapmış kişilerin dikmiş oldukları heykellere ait olan dört yazıt tanıtılacak ve ardından tanrı Ksanthos'un kimliğine ilişkin var olan tartışmalar değerlendirilerek yeni öneriler getirilecektir. Söz konusu yazıtlar ve tanrı Ksanthos'a ilişkin diğer yazıtlar genel olarak MS II-III. yüzyıllara tarihlendirilirler (Ksanthos'ta bulunduğu belirtilen yazıtlar için krş.

\footnotetext{
* Doç. Dr., Akdeniz Üniversitesi, Edebiyat Fakültesi, Eskiçağ Dilleri ve Kültürleri Bölümü, Antalya. nihaltuner@akdeniz.edu.tr
} 
Baker \& Thériault 2002, 304; Baker \& Thériault 2003, 432; Baker \& Thériault 2004, 318 (= SEG LIV 1464 [8]); Baker \& Thériault 2006, 284. Krş. Baker \& Thériault 2009, 65 dn. 5; Ayrıca Ksanthos'a ilişkin epigrafi çalışmaları için toplu olarak bkz. Tüner-Önen 2014, 307$322)$.

\section{Ata Yadigarı Tanrı Ksanthos Rahibi Apollonios'un Kent İçin Yaptığı Onurlandırma}

Üstten profilli, alttan ve sağdan kırık kireçtaşından heykel kaidesi. Tiyatronun hemen önünde konumlanan Batı Agora'nın batısındaki bazilika alanında sürdürülen temizlik çalışması sırasında, yapının kuzeybatısındaki duvar kalıntısında devşirme malzeme olarak tespit edilmiştir. Tam olmasa da ilk 6 satırına ait harflerin korunduğu yazıtta, tanrı Ksanthos'un rahipliğini üstlenmiş olan Apollonios isimli bir Ksanthoslunun vatanı onuruna diktirdiği heykel adağ 1 söz konusudur.

Ölçüler: yük. 0.47 m; gen. 0.48-46 m; der. 0.32 m; harf yük.: 0.025-0.03 m.

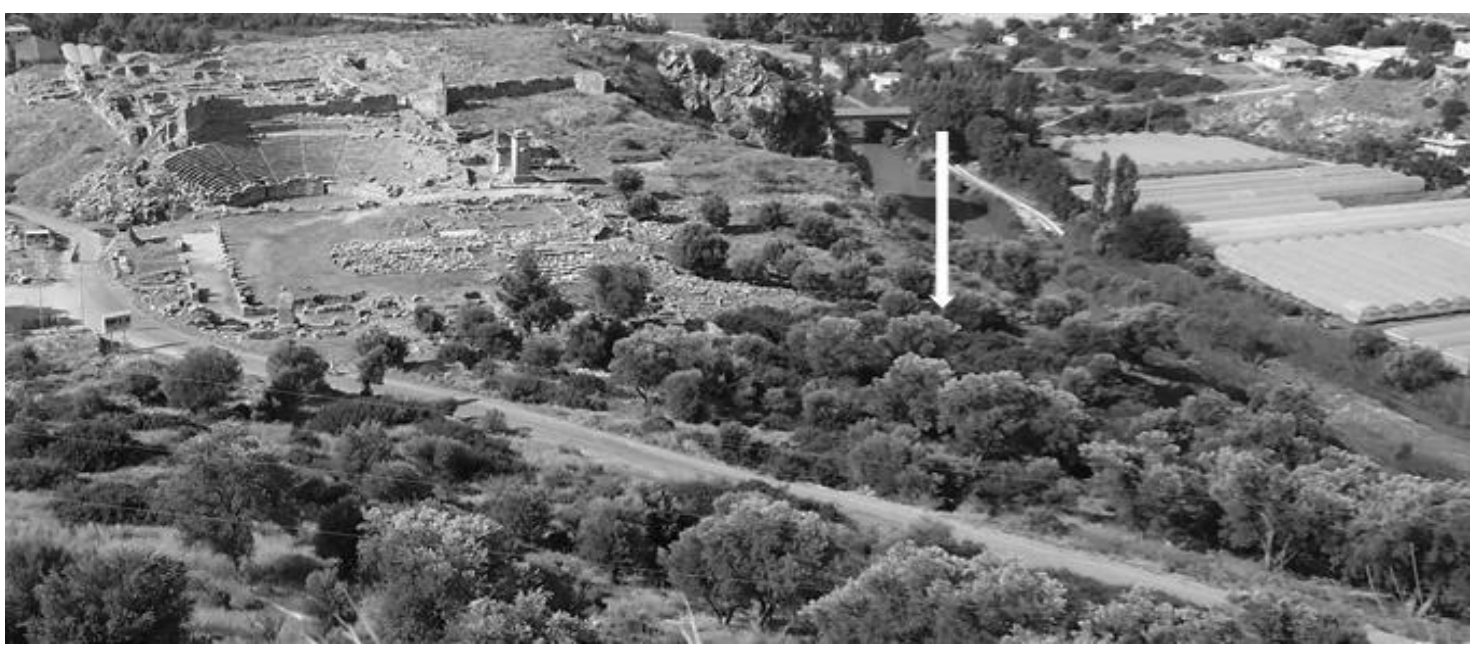

Аส

2

vos A $\pi \mathrm{o} \lambda \lambda \omega v$ víov

$\Xi \alpha ́ v-$

$4 \quad[\theta 10 \varsigma]$ iє $\rho \alpha \sigma \alpha ́ \mu \varepsilon v-$

[o $\pi \alpha] \tau \rho[\hat{\omega}] \mathrm{ov}$

$6 \quad \theta \varepsilon \circ \tilde{v}$

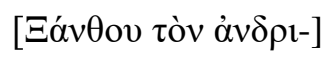

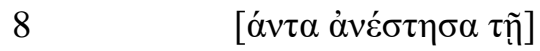

[ $\pi \alpha ́ \tau \rho 1 \delta 1]$

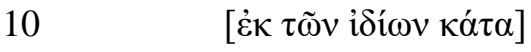

[ $\tau \grave{\alpha} \dot{\varepsilon} \psi \eta \varphi i ́ \sigma \mu \varepsilon v \alpha]$.

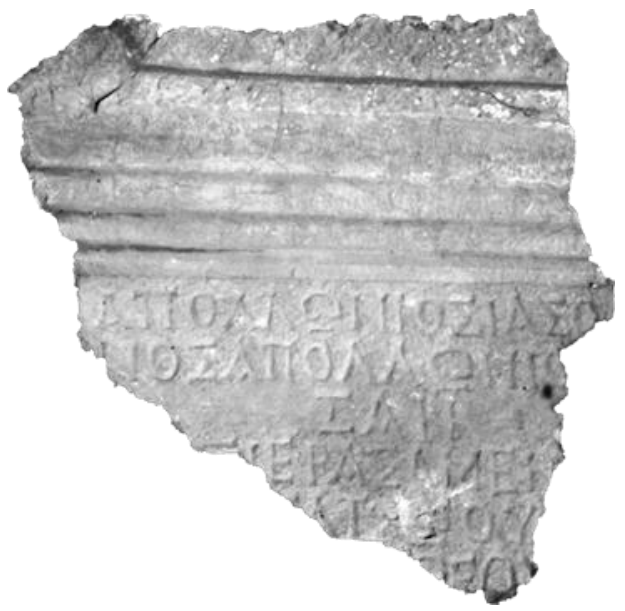

Ata yadigarl tanr Ksanthos'un rahipliğini yapmuş olan (ben) Apollonios oğlu Iason oğlu Ksanthoslu Apollonios, [oylama ile alınan kararlar uyarınca bu heykeli kendi kesemden vatan için diktim].

Yazıt harf karakterleri dolayısıyla Roma İmparatorluk Dönemi’ne tarihlendirilir. 
Str. 1-2: Theophorik Apollonios ve herophorik Iason isimleri hem kentte hem Lykia'da hem de güneybatı-batı Anadolu'da oldukça sık karşılaşılan isimlerdir (Krş. LGPN V/B, 41-47:

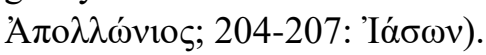

Yazıtın 6. satırından itibaren yapılan tamamlamalar kentten bu tanrıya ilişkin bilinen diğer yazıtlar göz önünde tutularak yapılmıştır. Zira bütün olarak ele geçen yazıtlar, alınan kararlar

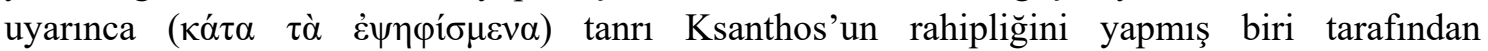

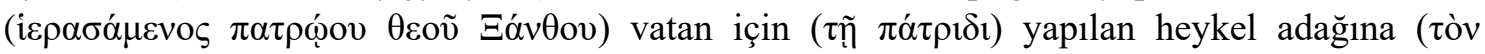

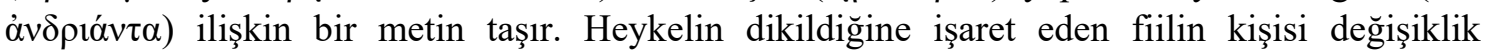
göstermektedir ( $\dot{\alpha} v \varepsilon ́ \sigma \tau \eta \sigma \alpha$ ya da $\dot{\alpha} v \varepsilon ́ \sigma \tau \eta \sigma \varepsilon)$. Fakat daha çok 1. tekil kişi belgelenmiştir.

\section{Ata Yadigarı Tanrı Ksanthos Rahibi Epaphrodeitos'un Kent İçin Yaptığı Onurlandırma}

Alt yarısı kırık, yazıtlı kısmı boylamasına kırılmış, üstten profilli ve alınlıklı, kireçtaşından heykel kaidesi. Yukarı şehri çeviren sur duvarının kuzeybatı bölümünün önünde bulunmaktadır. MS VII. yüzyıldaki sur onarım çalışmaları sırasında devşirme malzeme olarak kullanılmış, fakat sonrasında surdan kopup yamaca yuvarlanmıştır. Alınlığın iki köşesine köşe akroterleri işlenmiş ve ortaya tek satırlık bir yazıt yazılmıştır. Gövde kısmında ise 9 satır yazıt okunmaktadır.

Ölçüler: yük. 0.81 m; gen. 0.62 m; der. 0.32 m; harf yük. 0.030-0.035 m.
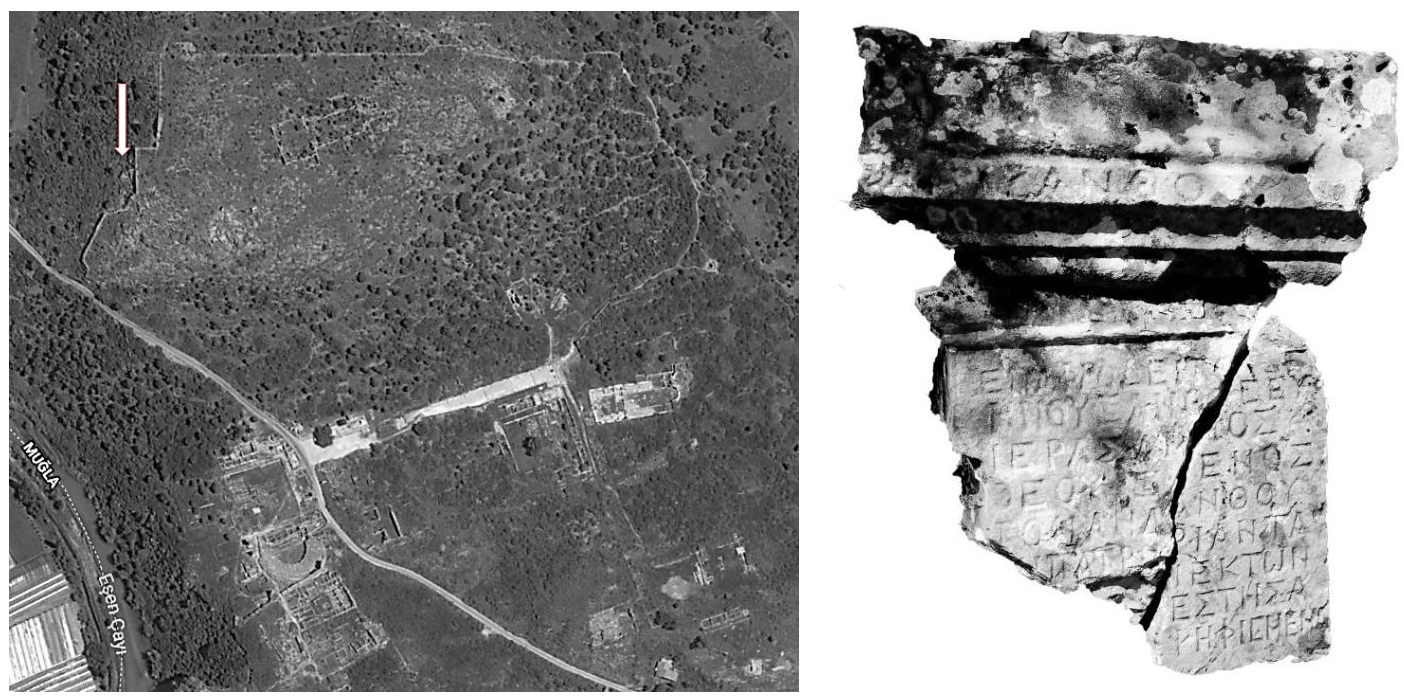

$\theta \varepsilon \circ \tilde{~} \Xi \alpha ́ v \theta 0 v$.

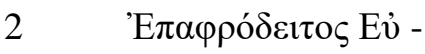
ท́vov $\Xi \alpha ́ v \theta$ ios

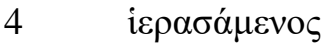
$\theta \varepsilon \circ \tilde{v} \Xi \alpha ́ v \theta o v$

$6 \quad \tau$ ò̀ $\alpha \grave{\alpha} v \delta \rho \operatorname{có}^{\prime} \tau \alpha$ $[\tau] \tilde{n} \pi \alpha ́ \tau \rho ı \delta เ ~ \varepsilon ̇ \kappa \tau \tilde{\omega} \nu$

$8 \quad[i \delta i ́ \omega v \alpha \dot{\alpha} v] \varepsilon \dot{\varepsilon} \sigma \tau \eta \sigma \alpha$

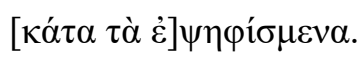

Tanrl Ksanthos'un.

Ata yadigar tanrı Ksanthos'un rahipliğini yapmış olan ben Euenos oğlu Ksanthoslu Epaphrodeitos, oylama ile alınan kararlar uyarınca bu heykeli vatan için kendi kesemden diktim.

Yazıt harf karakterleri dolayısıyla Roma İmparatorluk Dönemi’ne tarihlendirilir.

Str. 1: İlk satırda, ikinci satırdan itibaren başlayan adak yazıtından ayrı tutularak, tek başına 


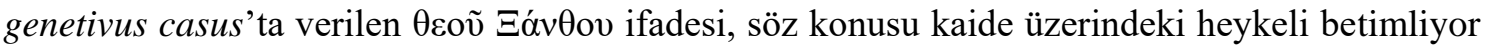
olabileceği gibi, Tanrı Ksanthos'un kutsal alanının sınırlarına da işaret ediyor olabilir (Genetivus casus'lu tanrı yazıtlarının tapınak/kutsal alan sınırlarına işaret etmesi hakkında bk. Akdoğu-Arca 2005, 47-58).

Str. 2-3: Epaphrodeitos'un babasının ismi, Ionia (Ephesos: SEG XXVII. 735; Kolophon: Macridy 1905, 172, 7), Pisidia (Pednelisos: SEG II. 727) ve Karia'dan (Miletos: IMiletos 125; Aphrodisias: Ferrary 2005, 256; Mylasa: IK Mylasa 544) bilinmesine karşın Lykia'da sadece bu yazıtta karşımıza çıkmaktadır $(L G P N \mathrm{~V} / \mathrm{B}, 161)$.

\section{Ata Yadigarı Tanrı Ksanthos Rahibi Aurelius Hermaios'un}

\section{Kent İçin Yaptığı Onurlandırma}

Kireçtaşından yazıtlı heykel kaidesi. MS VII. yüzyılda tüm Lykia kentlerini tehdit eden Arap akınları sebebiyle onarılan Roma İmparatorluk Dönemi kent surunun (Courtils 2003, 37) güney duvarında devşirme malzeme olarak kullanıldığı tespit edilmiştir. Alttan ve üstten profillendirilmiş olan kaidenin yazıtlı yüzeyi yana dönük şekilde örülmüştür. Kaide üzerinde, taşın kendinden kaynaklanan doğal çukurlar bulunmakta ve yazıtın bu çukurlara göre ayarlandığı görülmektedir. Toplam 12 satırdan oluşan yazıt net olarak okunabilmektedir.

Ölçüler: yük. 1.71 m; gen. 0.53 m; der. 0.53 m; harf yük.: 0.022-0.25 m.

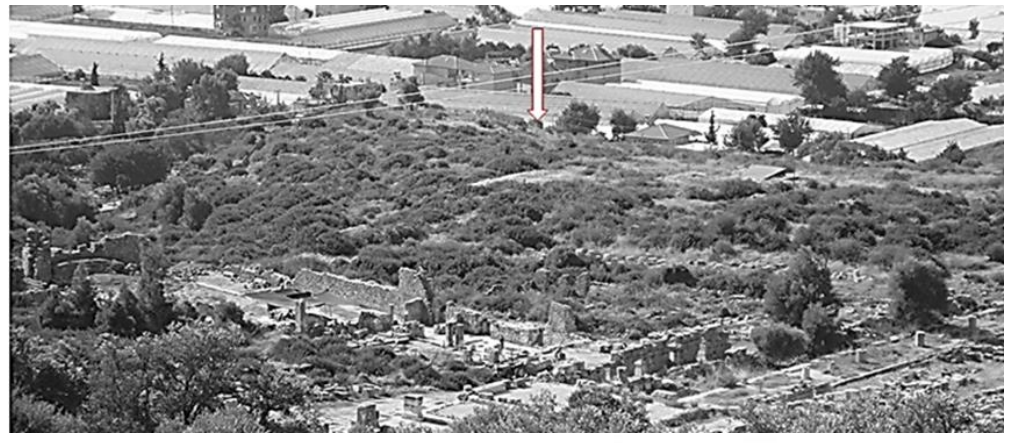

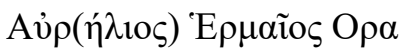

2 A $\lambda \varepsilon \xi \dot{\alpha} \alpha \delta \rho \rho 0 v \Xi \alpha ́ v-$

$\theta 1 o \varsigma$ i $\varepsilon \rho \alpha \sigma \alpha ́ \mu \varepsilon v o \varsigma$

$4 \tau$ นо๊̃ $\pi \alpha \tau \rho \omega-$

oṽ $\theta \varepsilon \circ \tilde{v} \Xi \alpha ́ v-$

$6 \quad \theta$ ov

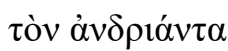

$8 \quad \dot{\varepsilon} \kappa \tau \tilde{\omega} \vee \mathfrak{i} \delta \dot{-}-$

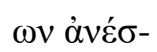

$10 \tau \eta \sigma \alpha$

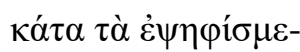
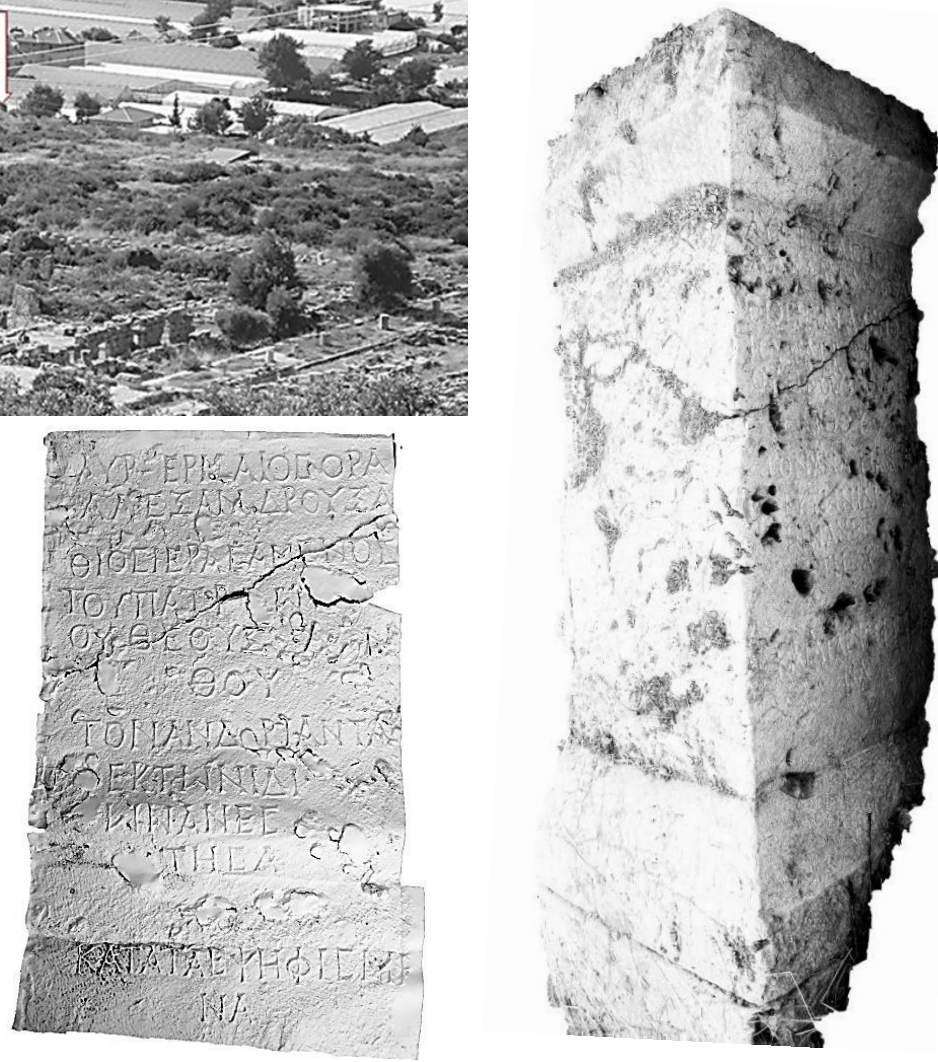

$12 v \alpha$.

Ata yadigarı tanrı Ksanthos'un rahipliğini yapmış olan ben Aleksandros oğlu (H?) oras oğlu Ksanthoslu Aur(elius) Hermaios bu heykeli, oylama ile alınan kararlar uyarınca kendi kesemden diktim. 
Yazıt Aurelius gens ismi dolayısıyla MS 212 sonrasına tarihlendirilir.

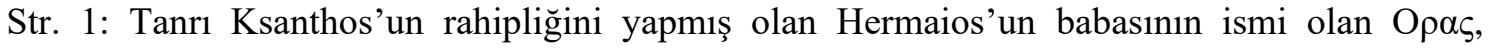
şimdiye kadar sadece Lykia'da - Ksanthos, Tlos, Pınara ve Telmessos- belgelenmiş yerel bir isimdir (Zgusta 1964, 379 § 1100-1; LGPN V/B 330).

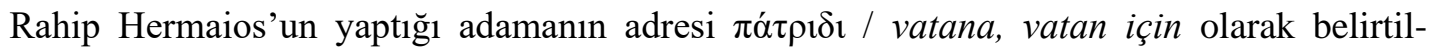
memiştir. Fakat ele geçen diğer yazıtlardaki kayıtlar göz önünde bulundurulduğunda bu adamanın da vatana yapıldığı düşünülebilir.

\section{Ata Yadigarı Tanrı Ksanthos Rahibi Aurelius Antigonos'un Kent İçin Yaptığı Onurlandırma}

Alttan ve üstten profillendirilmiş, kireçtaşından olan bu heykel kaidesi. Batı Agora'nın kuzeybatısında, Roma akropolis'ine doğru devam eden surların önünde, Ksanthos Nehri'ne doğru inen dik yamaç üzerinde bulunmaktadır. Söz konusu surlarda spolien malzeme olarak kullanılmış olmalıdır.

Ölçüler: yük. 1.08 m; gen. 0.51 m; der. 0.47 m; harf yük.: 0.035-0.40 m.

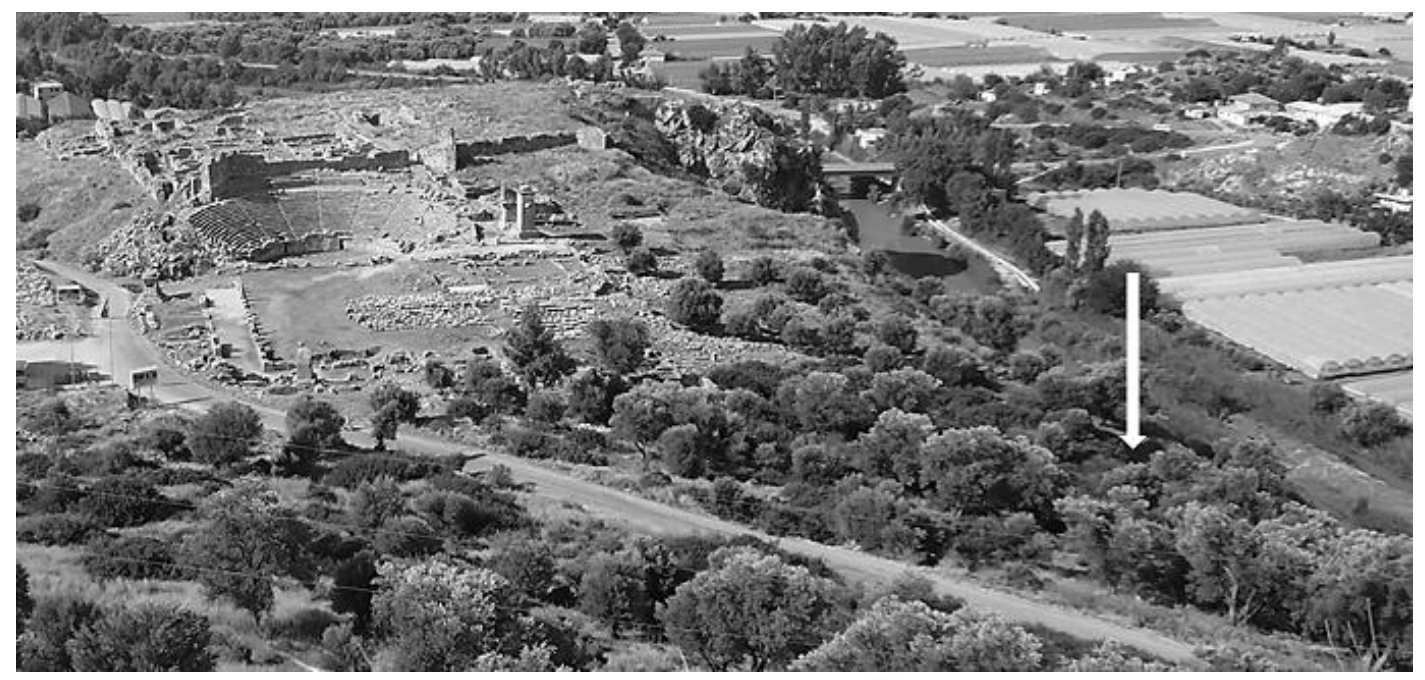

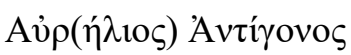

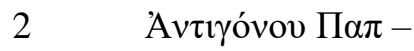

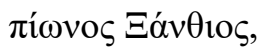

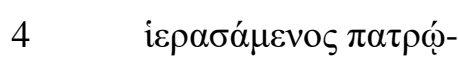

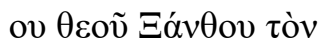

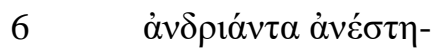

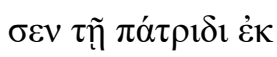

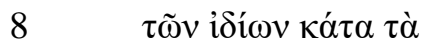

$\dot{\varepsilon} \psi \eta \varphi i ́ \sigma \mu \varepsilon v \alpha$.

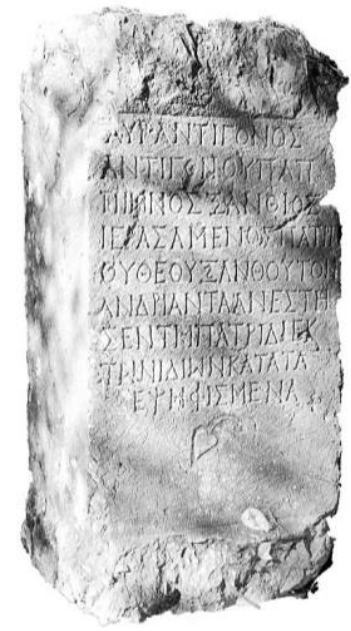

Ata yadigarı tanrı Ksanthos'un rahipliğini yapmış olan Pappion oğlu Antigonos oğlu Ksanthoslu Aur(elius) Antigonos, oylama ile alınan kararlar uyarınca bu heykeli vatan için kendi kesesinden dikti.

Yazıt Aurelius gens ismi dolayısıyla MS 212 sonrasına tarihlendirilir. 
Str. 1-2: Tanrı Ksanthos'un rahipliğini yapmış olan Antigonos ve babasının isimleri hem Lykia'da hem de güneybatı-batı Anadolu'da Hellenistik Dönem'den itibaren sıklıkla karş1laşı1lan isimlerdendir ( $L G P N$ V/B 30-31). Dedesinin ismi olan Pappion ise, dilsel miras açısından farklı kökenlere dayandırılmaktadır (Zgusta söz konusu ismin, Lall-name olabileceği gibi, Phrygia'dan ele geçen yazıtlardan yola çıkarak theophorik bir isim de olabileceğini; ayrıca hem Hellence hem de Latince'ye uyabilmesinin yanında, Mysia ve Bithynia'da belgelenen isimlerden dolayı Thrak kökenli bir isimlendirmeye de dayanıyor olabileceğini tartışır. Bu konuda bk. Zgusta 1964, 415 § 1199-24; Söz konusu isim için ayrıca bk. LGPN V/B 342).

\section{Ata Yadigarı (Patroos) Tanrı Ksanthos'a İlişkin Değerlendirme}

Ata yadigarı tanrı Ksanthos'a ilişkin ilk belirlemeyi Ch. Fellows yapmış ve Ksanthos kentinde tespit ettiği bir yazıtta geçen Ksanthos isminin, kentin aynı isimli nehrinin kişileştirilmiş formu olarak nehir tanrısına işaret ettiğini belirtmiştir (Fellows 1841, $167 \mathrm{nr} .1165=$ TAM II 294). Bu keşfin ardından Ksanthos kentinden bu tanrıya ilişkin bugüne kadar beş yazıt yayınlanmıştır

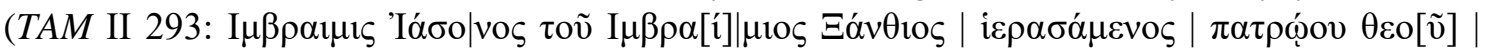

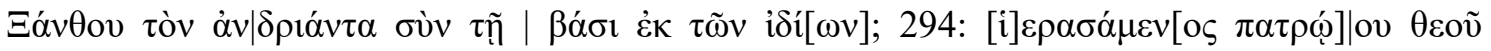

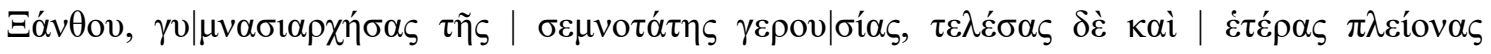

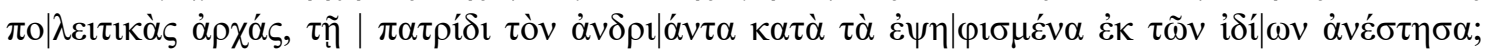

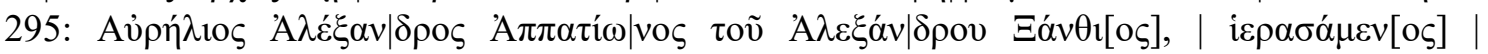

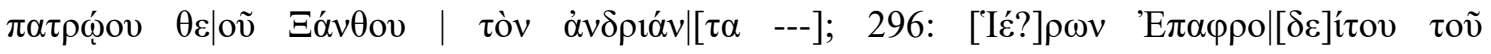

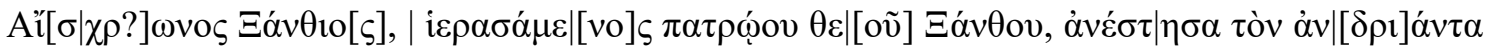

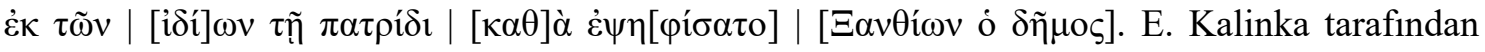

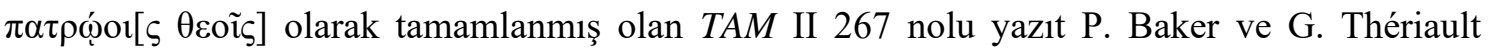
tarafından yeniden değerlendirilmiş ve taş üzerinde yapılan okuma sonucunda K $\lambda \alpha v ́ \delta$ เo

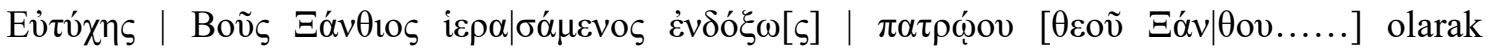
düzeltilmiştir. Baker \& Thériault 2009, 64 vdd.). P. Frei (1990, 1838 vd.) da, Roma İmparatorluk Dönemi'nde Lykia'daki tanrı kültlerine yönelik çalışmasında $\theta \varepsilon o ̀ s ~ \Xi \alpha ́ v \theta o \varsigma^{\prime} u$ Ch. Fellows gibi, bugün Eşen Çayı olarak anılan Ksanthos Irmağı'nın ( $\Xi \alpha ́ v \theta o \zeta \pi o \tau \alpha \mu$ ós) tanrısı olarak kabul eder ve Hellenistik Dönem'den itibaren tapınım görmüş olabileceğini düşünür $(1990,1851)$.

Ksanthos kentinin kutsal alanı Letoon ile birlikte antikçağ boyunca bölgenin idari ve kült merkezi olarak konumunu korumasında Ksanthos Nehri'nin önemli bir payı vardır. Esasen kent ile aynı isme sahip olan bu nehir sadece Ksanthos için değil, Lykia için de kıymetli bir yere

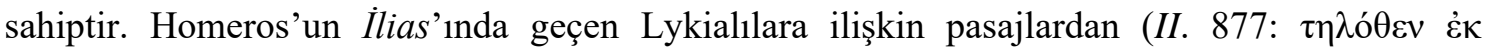

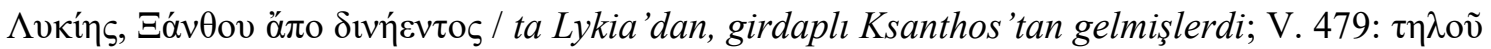

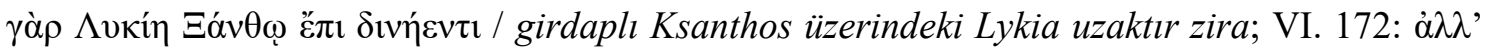

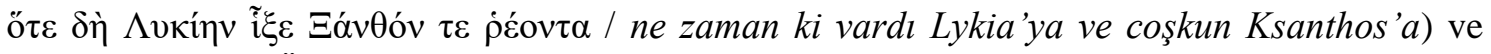
Herodotos'un MÖ 540 civarında Lykia'nın Persler tarafından ele geçirilmesini anlattığ bölümde geçen ifadelerden (I. 176, Herodotos burada Harpagos Ksanthos Vadisi'ne gelince Lykialıların az ayıda olmalarına karşın kalabalık Pers ordusuna karşı bu vadide savaşıp erdem gösterdiklerini aktarır), Ksanthos kenti ve vadisinin, Lykia uygarlığının erken dönemlerinde Lykia ile eşdeğer tutulduğu anlaşılmaktadır (Bk. Bryce 1986, 39 vd.; Mellink 1995, 33 vd.; Bryce 2006, 144 vdd.).

Lykia'nın diğer nehirleri arasında en çok değiniye sahip olan Ksanthos Nehri Panyasis’te

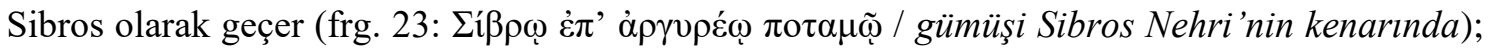

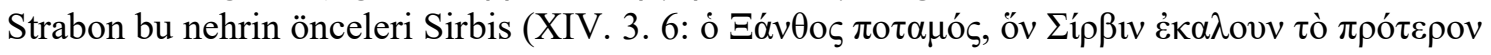
I önceleri Sirbis olarak adlandirılan Ksanthos Nehri) olarak adlandırıldığını aktarır; Eustathios ise sonradan Sirmis olarak yeniden isimlendirildiğini söyler (Comm. Il. III. 400. 21-23: A A $\alpha \theta \dot{\eta}$ 


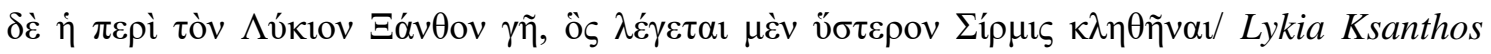
(Nehri) etrafindaki arazi verimlidir, daha sonraları Sirmis olarak adlandırıldı̆̆ söylenir). J. Tischler (1977, 134), bu isimlerinin Likçe ya da Frigce kökenli olabileceğini ve "parlak" anlamına geldiğini düşünür. Ksanthos Nehri coğrafik olduğu kadar, bölgenin dini inancının temellerinin atılmasında da önde gelen bir etkiye sahiptir. Öyle ki antik söylenceye göre bu nehri, kökenleri Luwilerin ana tanrıçasına dayanan (Bryce 1983, 1-13) Leto ortaya çıkartmıştır

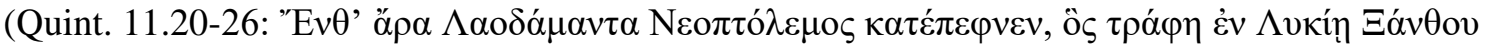

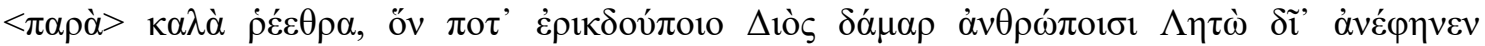

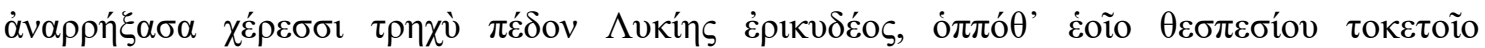

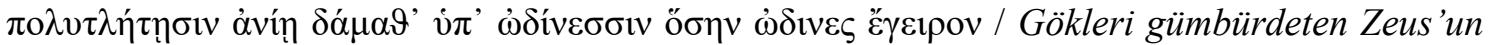
zevcesi Leto'nun, çocuklarını dünyaya getirdiği sıra doğum sancllarlyla kıvranırken ünlü Lykia'nın sert topră̆ını elleriyle eşeleyerek ortaya çıkardığl, Lykia'daki Ksanthos'un güzel akıntıları yanında büyüyen Neoptolemos'un Laodamas'ı öldürdüğ̈̈ yerde). Leto, Lykia'nın baş tanrısı olan Apollon ve kardeşi Artemis'i doğurduktan sonra çocuklarını yıkadığ bu nehri

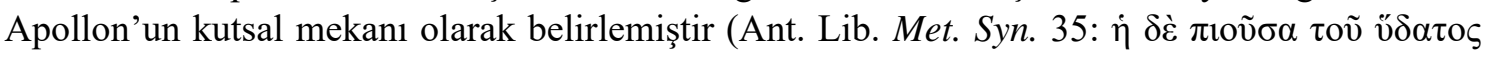

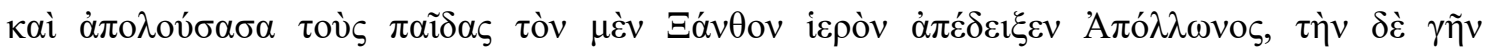

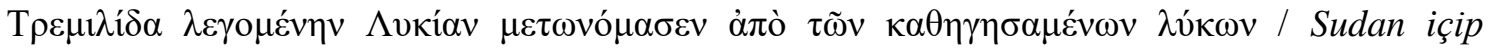
çocuklarını yıkayan Leto, Ksanthos'u Apollon'un kutsal mekanı olarak belirledi. Tremilis olarak söylenen yöreyi de önderlik eden kurtlardan dolayı Lykia olarak adlandırdı). MÖ I. yüzyılda yaşamış olan Diodoros da tanrı Apollon'un tapınağının bu nehrin kenarında

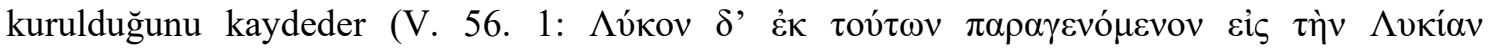

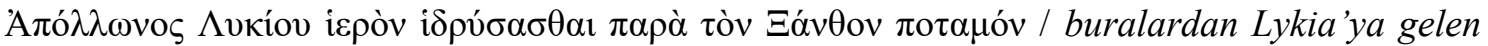
Lykos, Ksanthos Nehri'nin kenarında Lykia'lı Apollon'un tapınağını inşa etti). Aynı yüzyılda yaşamış Roma'lı şair Vergilius ise Aeneas isimli ünlü destanında Ksanthos Nehri'ni tanrı Apollon'un kışlık ikametgahı olarak anar (IV. 143-144: qualis ubi hibernam Lyciam Xanthique fluenta / deserit ac Delum inuisit Apollo / Kışını geçirdiği Lykia'yı, Xanthus Nehri'ni bırakıp da hani, anayurdu Delos'u görmeye geldiydi Apollon).

Antik dünyada nehirlerin kişileştirilerek bir tanrı gibi tapınım görmesi sık karşılaşılan bir durumdur. Homeros'un destanlarında hem Hellas'ta hem de Anadolu'da varlığı bilinen pek çok nehir mitolojik bir karakter olarak ortaya çıkmaktadır. Bunlar arasında en ünlüleri Hellas'ta Akheloos; Anadolu da ise Lykia'daki Ksanthos'la aynı ismi taşıyan Skamandros'tur. Akarnania ile Aitolia bölgeleri arasında akan Akheloos Okeanos'la Tethys'ten doğma üç bin ırmağın en

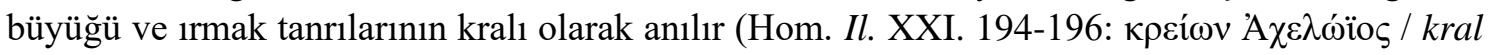
Akheloios). Troia ovasında akan ve insanlar tarafindan Skamandros olarak adlandırılan nehir ise

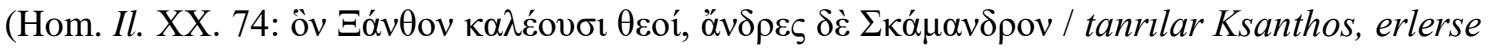
Skamandros olarak adladırırlar), diğerlerinin aksine Okeanos'un değil Zeus'un oğlu olarak

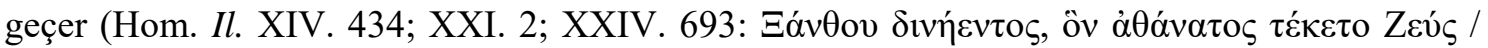
ölümsüz Zeus'in doğurduğu girdaplı Ksanthos'un) ve büyük bir tanrıdır (Hom. Il. XXI. 248: $\theta \varepsilon o ̀ \varsigma \mu \varepsilon ́ \gamma \alpha \varsigma$ / koca tanrı). Aktarımlar nehirlerin erken dönemden beri bir tanrı olarak sayg1 görmelerinin yanında tapınak ve rahipliklere de sahip olduklarını ortaya koymaktadır. Öyle ki Homeros Skamandros'un rahibi Dolopion'un adını anar (Il. V. 77 vd.: vं $\pi \varepsilon \rho \theta v ́ \mu o v \Delta o \lambda$ o

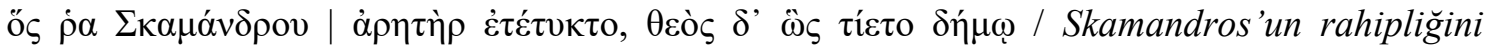
yapan, halk nezdinde tanrl gibi saygı gören cesur Dolopion'un (oğlu)). Pausanias da, Hellas'1 tasvir ettiği eserinde, Elis ile Arkadia bölgeleri arasında akan nehir tanrısı Alpheios'un

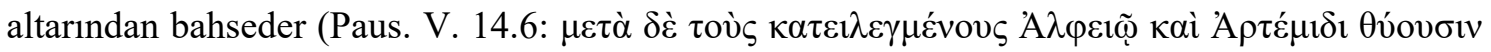

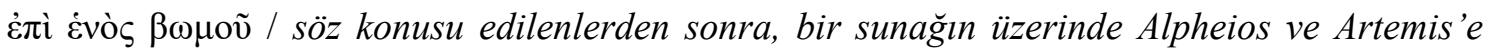
kurban keserler). Antik literatürde nehirlerin kişileştirilip birer tanrı gibi saygı ve tapınım 
gördüklerine dair daha pek çok örnek vardır (Bu konuda ayrıntılı bilgi için bk. Waser 1909, 2774-2815).

Lykia'da ise Limyros ve Meizoares nehir tanrılarının saygı gördüğü belgelenmiştir (Frei 1990, 1814; Efendioğlu 2010, 44-48). Limyra kentinden doğan ve Finike sahilinde Akdeniz'e dökülen Limyros Nehri'nin bir tanrı olarak tapınım gördüğüne ilişkin antik kaynaklarda ve yazıtlarda herhangi bir veri bulunmazken, sadece kentin darp ettiği bir sikke üzerinde betimlemesi bulunur (Aulock 1974, no. 114). Phaselis kenti teritoryum sinırları içerisinde yer

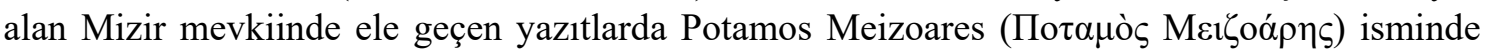
bir nehir ya da kaynak tanrısının adı geçer (İplikçioğlu, Çelgin \& Çelgin 2001, nr. 20-24 (= SEG LII 1440-144). Bugün Göynük Suyu olarak adlandırılan ve oldukça cılız akan bu çay muhtemelen antik dönemde daha gür akıyor olmalıydı. Esasen adından da anlaşılacağı üzere söz

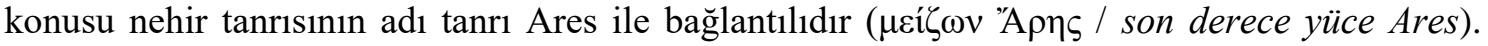
Söz konusu mevkiinin hemen kuzeyinde yer alan Ekizce/Sedir Yaylası denilen alanda tanrı Ares'e ait bir kült yeri bulunmaktadır. Buradan ele geçen yazıtlarda da duaları işiten epithetinin

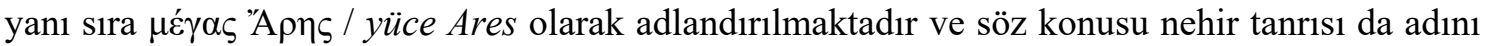
buradan almış olmalıdır (Söz konusu adlandırmalar ve tanrı Ares'in isminin bu akarsuya

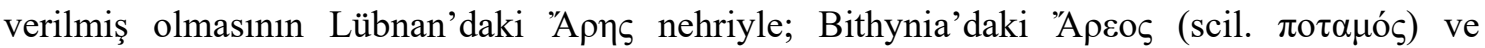

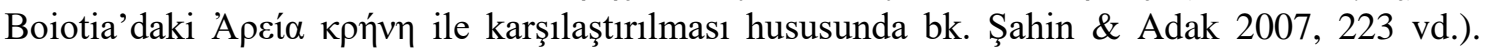
Yukarıda bahsi geçen anlatımlardan ortaya çıktığı üzere Ksanthos Nehri, Ksanthos kentine ve aktığ 1 yaklaşık $50 \mathrm{~km}$.lik vadiye hayat verdiği için erken dönemlerden itibaren kutsal sayılmış ve Lykia'nın baş tanrısı Apollon ile ilişkilendirilmiştir. Fakat Ksanthos Nehri her ne kadar kutsal sayılmış olsa da antik kaynakların hiçbirinde tanrı olarak adlandırılmamıştır. Öte yandan yazıtlarda kaydedilen tanrının da $\pi \alpha \tau \rho \tilde{\omega} о \varsigma$ $\theta$ cò $\varsigma$ olarak geçmesi, bunun nehir tanrısının ötesinde bir anlama sahip olduğunu düşündürmektedir.

Ch. Fellows ve P. Frei'1n aksine K. Keil (1850, 645 vd.) $\pi \alpha \tau \rho \tilde{\omega} о \varsigma$ $\theta \varepsilon o ̀ \varsigma ~ \Xi \alpha ́ v \theta o \varsigma^{\prime} u$ nehir tanrıs1 olarak değil de Ksanthos kentinin eponym Heros Ktistes'i olarak düşünmüş ve tezini Byzantionlu Stephanos'un Ksanthos kentine ilişkin maddesi, Dionysos Periegesis ile Panyasis'in anlatıları ile desteklemiştir. Zira Stephanos Byzantios, kentin adını Mısır ya da Giritli olan

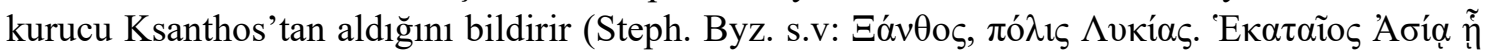

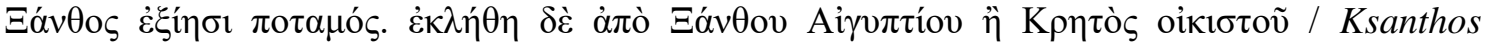
Lykia'nın kentidir. Hekataios Asia'da (der), yanından Ksanthos nehri geçer. Ksanthos adındaki Misır ya da Giritli kurucudan dolayı böyle adlandırllır). Dionysios Periegesis, kentin Lapeon'un oğlu, Pataros'un kardeşi olan Ksanthos tarafindan kurulduğunu anlatır (Dion. Per. V

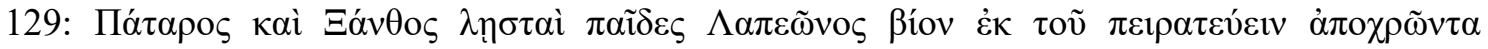

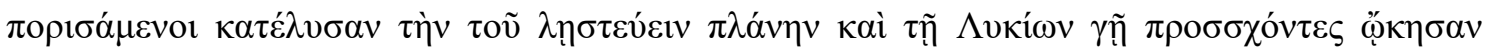

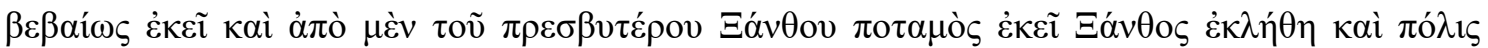
o $\mu \omega v v \mu \mathrm{o}$, / Lapeon'un eşkiya çocuklarl Patara ve Ksanthos korsanllktan geçindirdikleri hayatların devam ettirirken korsanlık yapma macerasina son verdiler ve Lykialıların ülkesine gelip orada kalıcı olarak yerleştiler; Oradaki bir nehir, yaş̧̧a büyük olan Ksanthos'tan dolayı Ksanthos olarak adlandırldd ve kent de aynı isimle anıldi). Panyasis ise Ksanthos'u, Tloos ve

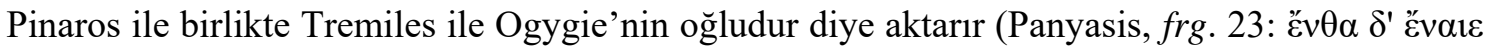

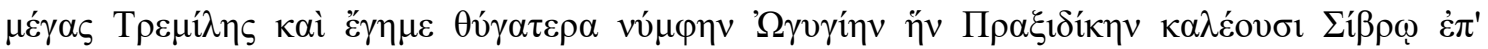

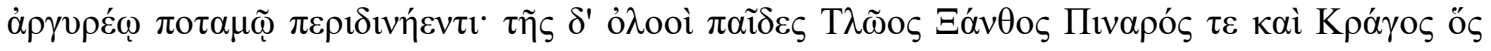

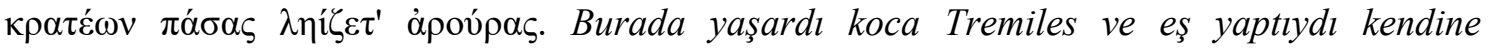
Praksidike diye de çağırdıkları nymphe Ogygie'yi, gümüşi renkte girdaplanan Sibros Nehri klyısında. Azgın çocukları Tloos, Ksanthos ve Pinaros ve de tüm tarlaları zorla gasp eden Kragos'tu). 
Fakat Ksanthos gibi ktisteslere tanrıdan çok bir heroos olarak tapınıldığı bilinmektedir. Her ne kadar bir kahraman olarak düşünülen ve sonradan tanrılaştığına inanılan Herakles'e Patroos

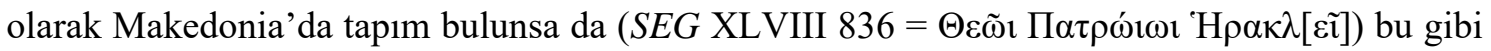
durumlar panhellenik anlamda yaygındır ve oldukça istisna örneklerdir (Farnell 1921, 269). Ayrıca patroos olarak belirtilen tanrılar genellikle bu ktistes ya da oikesteslerin taptıkları tanrılar olarak görülmektedir. Tanr1 olarak ifade edilen Ksanthos'un aldı̆̆1 $\pi \alpha \tau \rho \tilde{\omega} o \varsigma$ $\theta \varepsilon o ́ \varsigma$ epitheti

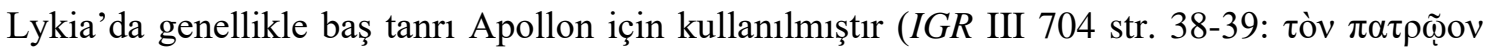

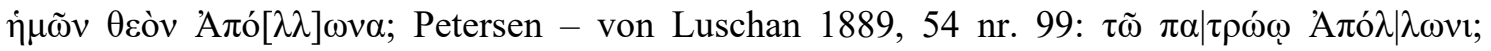

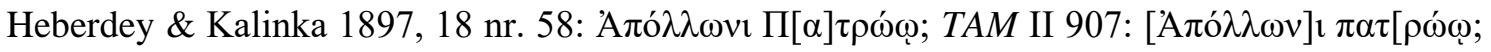

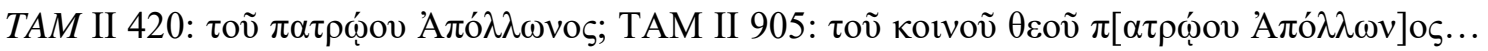

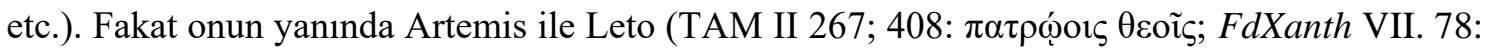

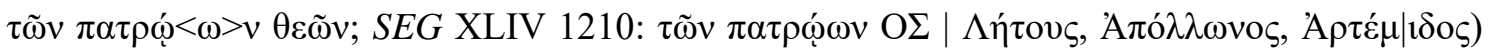

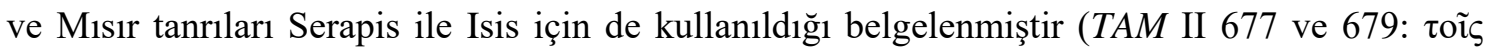

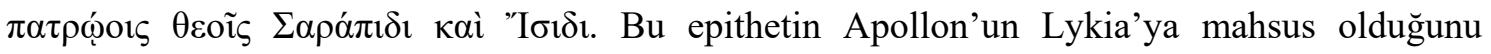
vurgulayıp diğer tanrılar nezdindeki önemini ortaya çıkarmak amacıyla kullanılması hususunda

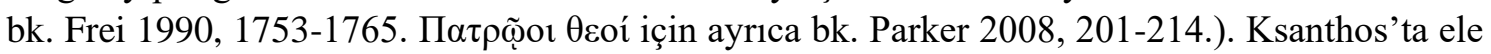

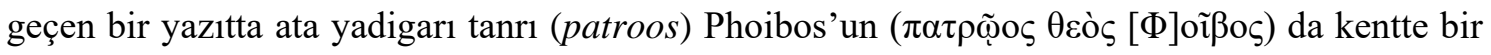
rahipliğinin bulunduğu öğrenilmektedir (Baker \& Thériault 2006, 284).

\section{Sonuç}

Daha önceden yayımlanmış olan Ksanthos Patroos yazıtları ile burada ele alınan yazıtlar her ne

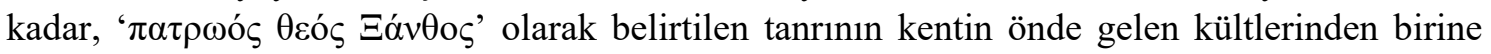
sahip olduğunu; Ksanthos'ta tanrıya ait bir tapınağın bulunduğunu ve rahiplerinin, oylama sonucu alınan kararlar uyarınca heykel adağında bulunduklarını ortaya koymaktalarsa da, tanrının kimliğininin -Nehir tanrı ya da heros ktistes olarak- kesinleştirilmesi hususunu tartışmalı bırakmaktadırlar. Esasen 'Ata Yadigarı Tanrı Ksanthos'un hem kent hem nehir hem de doğrudan tanrı Apollon ile bağlantılı olduğu söylenebilir. Zira $\Xi \alpha ́ v \theta o \varsigma$ adlandırması yine nehir, kent ve Apollon'a ilişkin alegorik bir epitheton olmalıdır. Bu kapsamda Demeter'in sarışın ol-

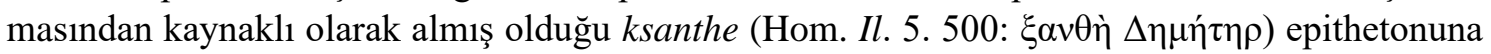
benzer şekilde buradaki Apollon'a da sarışın olmasından dolayı ksanthos (sarı) sıfatı verilmiş olabilir. Böylece Likya Birliği'nin ortak tanrısı olan; Ksanthos'un hemen yanıbaşındaki Letoon'da Leto ve Artemis ile birlikte patrooi theoi olarak görülen ve Lykia'nın birçok kentinde patroos olarak adlandırılan Apollon ile farklı bir tanrı olduğunu belirtmek ve doğumunun ardından Ksanthos Nehri'nde yıkanmasıyla oluşan bağla da kökenini daha çok Ksanthos kentine

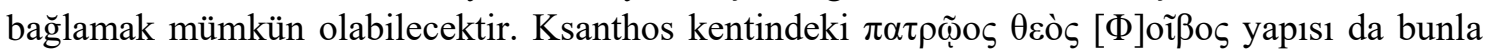
benzer ve aynı nedenlerle bu şekilde yazılmış olsa gerektir. Ayrıca tanrılara yönelik bu tür sahiplenme ve tanımlamalar İkinci Sophistik Dönemi’n karakteristik özellikleri arasındadır.

Son olarak, şimdiye kadar ele geçen söz konusu yazıtların hepsinin de, MS VII. yüzyılda Arap akınlarına karşı tamir edilen kent surunun, Ksanthos Nehri boyunca devam eden batı ve kuzeybatı kısmında devşirme malzeme olarak kullanılması dolayısıyla tanrıya ilişkin olası tapınağın, "Batı Agora" olarak adlandırılan agorada, Ksanthos Nehri'ne bakan bir konumda olduğu düşünülebilir. Yazıtlarda adı geçen rahiplerin alınan bir karar uyarınca adadıkları söz konusu heykeller de burada dikilmiş ve külte ilişkin ritüeller de burada uygulanmış olmalıdır. 


\section{KAYNAKÇA}

\section{Antik Kaynaklar}

Ant. Lib. (= Antonius Liberalis) Kullanılan Metin ve Çeviri: I. Cazzaniga (ed.), Metamorphoseon Synagoge. Milan 1962, 12-77.

Diod. (= Diodorus Siculus, Bibliotheke Historike) Kullanılan Metin ve Çeviri: R. M. Geer (ed.), Diodorus of Sicily. London, New York 1947.

Dion. Per. (= Dionysios, Periegesis) Kullanılan Metin: F. C. Matthiae (ed.), Dionysii, Orbis Terrarum Descriptio. Francofurti ad Moenum 1817.

Eustath. Comm. Il. (= Eustathius, Commentarii ad Homeri Iliadem) Kullanılan Metin: M. van der Valk (ed.), Eustathii archiepiscopi Thessalonicensis commentarii ad Homeri Iliadem pertinentes. Leiden 19711987.

Hdt. (= Herodotos, Historiai) Kullanılan Metin ve Çeviri: A. D. Godley (ed.), Herodotus, Libri I-IV. London 1975.

Hom. Il. (= Homeros, Ilias) Kullanılan Metin ve Çeviri: A. Erhat \& A. Kadir, Homeros, Ilyada. İstanbul $1993^{7}$.

Panyasis, frg. (= Panyasis, Fragmenta) Kullanılan Metin: A. Bernabe (ed.), Poetarum Epicorum Graecorum testimonia et fragmenta, Pt. 1. Leipzig 187: 174-176; 179-187.

Paus. (= Pausanias, Periegesis tes Hellados) Kullanılan Metin ve Çeviri: W. H. Jones (ed.), Pausanian Description of Greece. New York 1918-1935.

Quint. (= Quintius Smyrneus, Posthomerica) Kullanılan Metin ve Çeviri: F. Vian (ed.), La suite d'Homere. Paris 1963-1969.

Steph. Byz. (= Stephanos Byzantios, Ethnika) Kullanılan Metin: A. Westermann (ed.), Stephani Byzantii, Ethnikon. Libsae 1839.

Strab.(= Strabon, Geographika) Kullanılan Metin ve Çeviri: H. L. Jones (ed.), The Geography of Strabo. Vols. I-VIII. London, New York 1917-1932.

Verg. Aen. (= Vergilius, Aeneis) Kullanılan Metin ve Çeviri: H. Fairclough (ed.), Virgil, Eclogues, Georgics, Aenid, the Minor Poems. Mass.-London 1966-1967.

\section{Modern Literatür}

Akdoğu-Arca E. N. (2005). "The Genitive Case on Altares from Asia Minor indicating a Boundary Inscription”. Gephyra (2005) 47-58.

Baker P. \& Thériault G. (2002). Anatolia Antiqua X (2002) 302-305.

Baker P. \& Thériault G. (2003). Anatolia Antiqua XI (2003) 431-435.

Baker P. \& Thériault G. (2004). Anatolia Antiqua XII (2004) 316-319.

Baker P. \& Thériault G. (2006). Anatolia Antiqua XIV (2006) 284-286.

Baker P. \& Thériault G. (2009). "Notes sur quelques inscriptions grecques de Lycie, Xanthos, Arykanda et Kadyanda, et deux nouvelles inscriptions xanthiennes". REG 122 (2009) 63-84.

Bryce T. R. (1983). "The Arrival of the Goddess Leto in Lycia”. Historia 32 (1983) 1-13.

Bryce T. R. (1986). The Lycians in Literary and Epigraphic Sources. Copenhagen 1986.

Bryce T. R. (2006). The Trojans and Their Neighbours. New York 2006.

des Courtils C. (2003). Dünya Kültür Mirası Kentlerinden Ksanthos ve Letoon Rehberi. İstanbul 2003.

Efendioğlu T. (2010). Lykia'da Yerel Tanrı ve Tanrıçalar. İstanbul 2010.

Fellows Ch. (1841). An Account of Discoveries in Lycia. London 1840.

Ferrary J.-L. (2005). 'L'onomastique dans les provinces orientales de l'empire à la lumière du dossier des mémoriaux de délégations de Claros". Cahrlers du Centre Gustave Glotz 19 (2008) 247-278.

Frei P. (1990). "Die Götterkulte Lykiens in der Kaiserzeit”. ANRW II 18.3 (1990) 1730-1864.

Heberdey R. \& Kalinka E. (1897). Bericht über zwei Reisen im südwestlichen Kleinasien. Vienna 1897.

IGR Inscriptiones Graecae ad res Romanas pertinentes. 
IK Mylasa. W. Blümel, Die Inschriften von Mylasa. 2 vols. Inschriften griechischer Städte aus Kleinasien, 34-35. Bonn 1987-1988.

IMiletos. D. F. McCabe, Miletos Inscriptions. Texts and List. The Princeton Project on the Inscriptions of Anatolia. The Institute for Advanced Study. Princeton 1984.

İplikçioğlu B., Çelgin G. \& Çelgin A. V. (2001). Doğu "Kuzeydoğu Lykia - Güneybatı Pisidia Epigrafik Tarihi Coğrafi Yüzey Araştırmaları Projesi 1999 Çalışmaları". AST 18.1 (2001) 241-245. Ankara.

JÖAI Jahreshefte des Osterreichischen Archäologischen Institutes in Wien. Vienna 1898-.

Keil K. (1850). "Griechische Inschriften aus Lykien". Philologus 5 (1850) 643-674.

Klementa S. (1993). Gelagerte Flussgötter des Spaethellenismus und der römischen Kaiserzeit. Köln 1993.

$L G P N$ V. B Balzat J. -S., Catling R. W. V., Chiricat É. \& Marchand F., A Lexicon of Greek Personal Names, Volume V. B: Coastal Asia Minor: Caria to Cilicia. Oxford 2014.

Macridy T. (1905). “Altertümer von Notion”. JÖAI 8 (1905) 155-173.

Megrelis M. (2013). Religion and Cultural Conservatism in Lycia: Xanthos and the Letoon. Ph.D. Thesis, School of History, Classics and Archaeology, The University of Edinburg, Edinburg 2013.

Mellink M. J. (1995). "Homer, Lycia, and Lukka". Eds. J. B. Carter \& S. P. Morris. The Ages of Homer: A Tribute to Emily Townsend Vermeule (1995) 33-42. Austin.

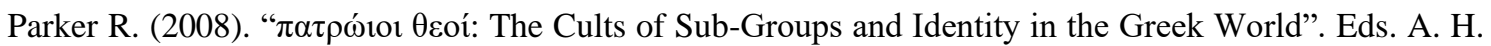
Rasmussen \& S. W. Rasmussen. Religion and Society. Rituals, Resources and Identity in the Ancient Graeco-Roman World (2008) 201-214. Roma.

Petersen E. \& von Luschan F. (1889). Reisen in Lykien Milyas und Kibyratis Reisen im Südwestlichen Kleinasien II. Wien 1889.

RE Paulys Realencyclopädie der classischen Altertumswissenschaft.

REG Revue des Études Grecques.

SEG Supplementum Epigraphicum Graecum.

Sheppard A. R. R. (1984-1986). "Homonoia in the Greek Cities of the Roman Empire". AncSoc 15-17 (1984-1986) 229-252.

Şahin S. \& Adak M. (2007). Stadiasmus Patarensis. Itinera Romana Provinciae Lyciae. İstanbul 2007.

Tischler J. (1977). Kleinasiatische Hydronomie. Wiesbaden 1977.

Tüner-Önen N. (2014). "Yeni Yazıtlar Işı̆ı̆ında Ksanthos Epigrafi Çalışmaları". Cedrus II (2014) 307-322.

von Aulock H. (1974). Die Münzprägung des Gordian III und der Tranquillina in Lykien. Berlin 1974

Waser O. (1909). "Flussgötter". RE VI (1909) 2774-2815.

Zgusta L. (1964). Kleinasiatische Personennamen. Prag 1964. 